\title{
Benign enlargement of subarachnoid spaces: a cause of subdural haemorrhage in toddlers
}

\author{
Asthik Biswas, ${ }^{1}$ Farha Furruqh, ${ }^{1}$ Suresh Thirunavukarasu, ${ }^{2}$ Sankar Neelakantan ${ }^{1}$
}

${ }^{1}$ Department of Radiology, St Johns Medical College Hospital, Bangalore, Karnataka, India ${ }^{2}$ Department of Neurology, Indira Gandhi Government General Hospital and Post Graduate Institute, Puducherry, Puducherry, India

\section{Correspondence to}

Dr Suresh Thirunavukarasu, sureshy2001@rediffmail.com

Accepted 17 April 2016
CrossMark

To cite: Biswas $\mathrm{A}$

Furruqh $\mathrm{F}$,

Thirunavukarasu $S$, et al. BMJ Case Rep Published online: [please include Day Month Year] doi:10.1136/ bcr-2016-215753

\section{DESCRIPTION}

A 7-month-old male child (patient 1) was referred for a CT of the brain for evaluation of macrocephaly. His head circumference was $48 \mathrm{~cm}$ ( $>95$ th centile). He was otherwise normal and his developmental milestones were normal for age. The CT showed enlarged subarachnoid spaces in the frontal and temporal lobes (figure 1). A chronic subdural haemorrhage $(\mathrm{SDH})$ was noted in the right frontal lobe (figure 1).

A 2-month-old male child (patient 2) was referred for CT of the brain following a fall. The CT showed an acute SDH in the left frontal lobe (figure 2). Also noted were enlarged subarachnoid spaces in the frontal and temporal lobes (figure 2). This patient had a normal head circumference for age. Similar to patient 1 , his developmental milestones were normal.

On the basis of clinical history, examination and CT findings, the diagnosis of benign enlargement of subarachnoid spaces (BESS) was made for both infants.

BESS is not an uncommon finding in normal infants. ${ }^{1}$ Children usually present with macrocephaly or a rapidly enlarging head circumference, resulting in a head circumference $>95$ th centile for age. The absence of macrocephaly, however, does not preclude the diagnosis of BESS. ${ }^{2}$ Typical radiological findings include widened subarachnoid spaces in the frontal and temporal lobes, and the absence of significant ventriculomegaly. ${ }^{2}$ These patients usually show normal development, although transient delayed milestones may be seen. The condition usually resolves spontaneously by 2 years of age. ${ }^{1}$ The cause of enlarged subarachnoid spaces in these children is not known, although delayed maturation of the arachnoid villi has been proposed as a possible mechanism. ${ }^{2}$

The diagnosis of BESS may be complicated by the finding of SDH. ${ }^{3}$ The underlying theory is that stretching of the bridging subdural veins due to enlargement of the cerebrospinal fluid (CSF) spaces predisposes to developing $\mathrm{SDH} .{ }^{4} \mathrm{SDH}$ in children with BESS may occur spontaneously or as the result of minor trauma. ${ }^{2}$ The presence of SDH in children $<2$ years of age, however, also raises the possibility of non-accidental injury (NAI). For social and medicolegal reasons, it is important to make this distinction. The absence of other features of NAI, such as skeletal fractures, cerebral contusions and a generally benign clinical course points to a diagnosis of BESS rather than NAI. ${ }^{3}$

Another entity mimicking BESS is type 1 glutaric aciduria, which on imaging may show widened subarachnoid spaces and SDH. ${ }^{5}$ Other findings seen in glutaric aciduria are white matter and basal ganglia signal changes. Also, children with glutaric aciduria are symptomatic (developmental delay, dystonia, encephalopathy) as opposed to children with BESS. 5

It is important to know the clinical presentation and imaging features to differentiate BESS from

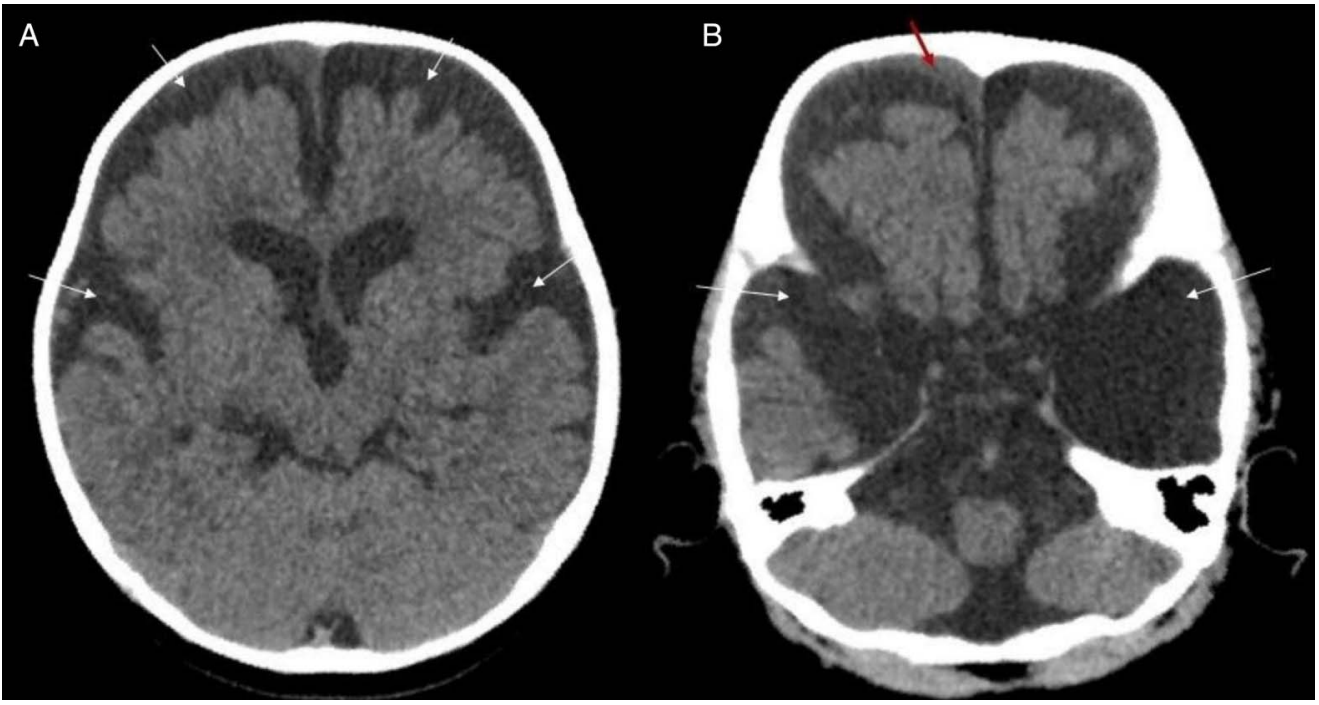

Figure 1 (A) Axial section of brain CT showing widened subarachnoid spaces in the frontal and temporal lobes (white arrows). (B) Axial section of brain CT showing a chronic subdural haemorrhage in the right frontal lobe extending into the interhemispheric fissure (red arrow). Also seen are widened subarachnoid spaces in the temporal lobes (white arrows). 


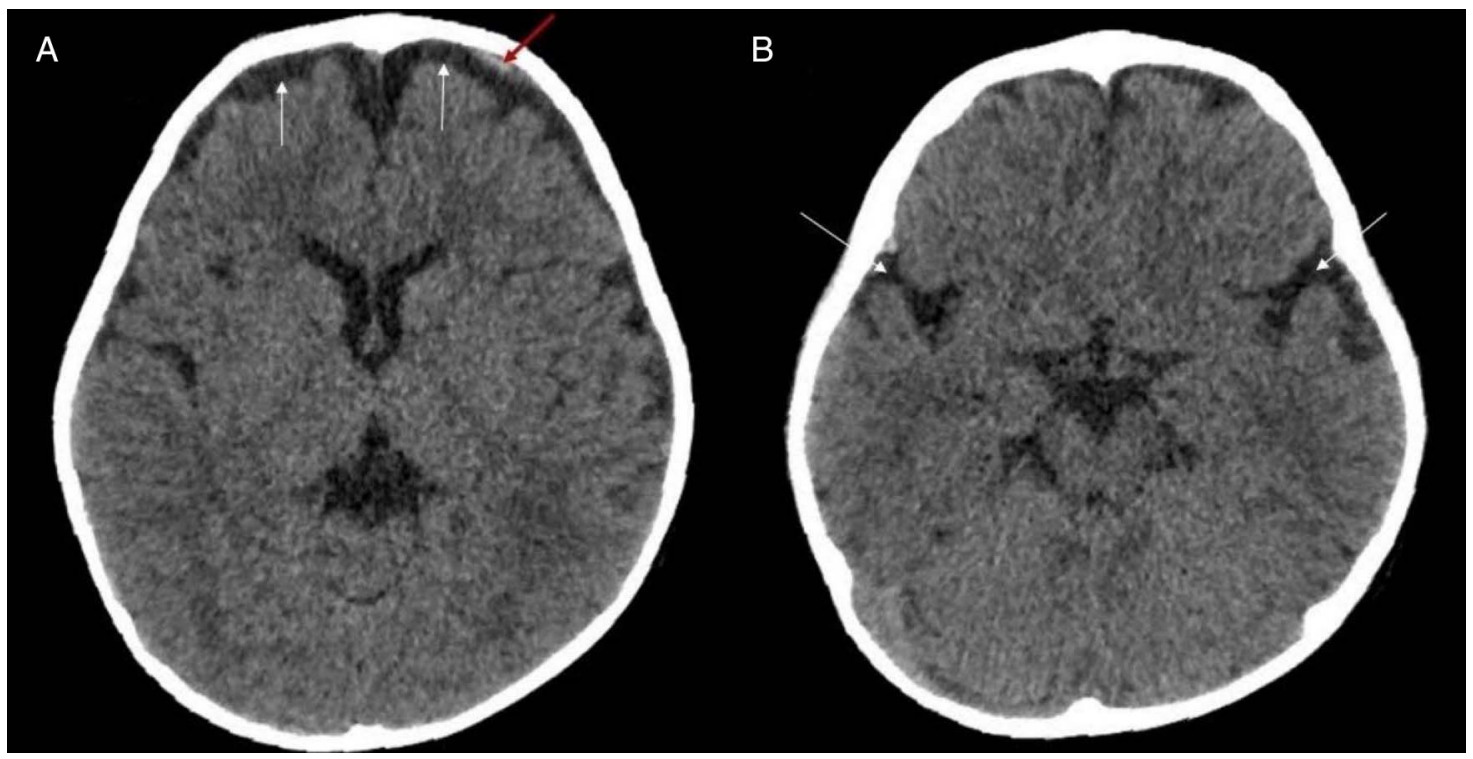

Figure 2 (A) Axial section of brain CT showing an acute subdural haemorrhage in the left frontal lobe (red arrow), with widened subarachnoid spaces in the frontal lobes (white arrows). (B) Axial section of brain CT showing widened subarachnoid spaces in the temporal lobes (white arrows).

'non-benign' causes of subarachnoid space widening such as NAI and type 1 glutaric aciduria.

\section{Learning points}

- Benign enlargement of subarachnoid spaces (BESS) is a common cause of macrocephaly.

- Children with BESS are usually asymptomatic, in contradistinction to glutaric aciduria and non-accidental injury (NAI), which on imaging mimic BESS.

- BESS may be associated with subdural haemorrhage. It is important to differentiate this from NAl as the latter has social and medicolegal implications.
Contributors $A B$ conceptualised and drafted the manuscript. FF reviewed the literature of the subject. ST was the clinician in charge of the patients and reviewed the manuscript. SN edited the manuscript. All the authors reviewed and approved the final manuscript.

Competing interests None declared.

Patient consent Obtained.

Provenance and peer review Not commissioned; externally peer reviewed.

\section{REFERENCES}

1 Hamza M, Bodensteiner JB, Noorani PA, et al. Benign extracerebral fluid collections: a cause of macrocrania in infancy. Pediatr Neurol 1987;3:218-21.

2 Barkovich AJ, Raybaud C. Pediatric neuroimaging. 5th edn. Philadelphia: LWW, 2011.

3 McNeely PD, Atkinson JD, Saigal G, et al. Subdural hematomas in infants with benign enlargement of the subarachnoid spaces are not pathognomonic for child abuse. AJNR Am J Neuroradiol 2006:27:1725-8.

4 Papasian NC, Frim DM. A theoretical model of benign external hydrocephalus that predicts a predisposition towards extra-axial hemorrhage after minor head trauma. Pediatr Neurosurg 2000;33:188-93.

5 Brismar J, Ozand PT. CT and MR of the brain in glutaric acidemia type I: a review of 59 published cases and a report of 5 new patients. AJNR Am J Neuroradiol 1995; 16:675-83.

Twitter Follow Sankar Neelakantan at @drsankar23

Copyright 2016 BMJ Publishing Group. All rights reserved. For permission to reuse any of this content visit http://group.bmi.com/group/rights-licensing/permissions.

BMJ Case Report Fellows may re-use this article for personal use and teaching without any further permission.

Become a Fellow of BMJ Case Reports today and you can

- Submit as many cases as you like

- Enjoy fast sympathetic peer review and rapid publication of accepted articles

- Access all the published articles

- Re-use any of the published material for personal use and teaching without further permission

For information on Institutional Fellowships contact consortiasales@bmjgroup.com

Visit casereports.bmj.com for more articles like this and to become a Fellow 